Revista

A Cor

das Letras

\title{
O filme diary of a wimpy kid no ensino da língua inglesa
}

\author{
The movie "diary of a wimpy kid" in the teaching of the English language
}

\author{
Luiz Sérgio Alzair Alzão \\ Universidade Estadual de Maringá \\ Marengá, Paraná, Brasil \\ Alba Krishna Topan Feldman \\ Universidade Estadual de Maringá \\ Marengá, Paraná, Brasil
}

Resumo: O objetivo deste artigo é destacar a funcionalidade da imagem como modalidade de construção de significados e apresentar sugestões de letramento com o uso de filmes como uma das modalidades no ensino da língua inglesa, para nível fundamental. Nesse caso específico, o trabalho será embasado no filme Diary of a Wimpy Kid (2010), (Diário de um Banana), com legendas em inglês, adaptado do livro homônimo de autoria de Jeff Kinney (2008). Atividades dessa natureza podem auxiliar o profissional de ensino a tornar sua aula mais dinâmica, interessante e despertar o interesse do aluno. $\mathrm{O}$ aporte teórico principal terá como base a obra de Jane Sherman, Using Authentic Video in the Language Classroom (2003), que define alguns conceitos de como trabalhar um vídeo ao ministrar uma aula de língua inglesa; e de Gunther Kress, The Literacy in the New Media Age (2003), que discorre sobre a presença cada vez maior da imagem no processo de comunicação.

Palavras-chave: Multimodalidades. Letramentos. Jeff Kinney. Diário de um Banana.

\begin{abstract}
The purpose of this article is to highlight the functionality of the image as a means of constructing meanings, and to present suggestions with the use of films as one of the modalities in the literacy of the English language for the fundamental level. In this specific case, the work will be based on the film Diary of a Wimpy Kid (2010), with English subtitles, adapted from the eponymous book (2008) authored by Jeff Kinney. Activities of this nature can help the teaching professional to make his/her classroom more dynamic, interesting and awaken the student's interest. The main theoretical contribution will be based on Jane Sherman's book Using Authentic Video in the Language Classroom (2003), which defines some concepts of how to use a video while teaching an English language class; And Gunther Kress's The Literacy in the New Media Age (2003), which discusses about the increasing presence of the image in the process of communication.
\end{abstract}

Key-words: Multimodalities. Literacy. Jeff Kinney. Diary of a Wimpy Kid.

\section{INTRODUÇÃO}

A decisão entre se manter preso ao livro ou navegar nas multimodalidades de comunicação oferecidas atualmente pode fazer uma grande diferença na dinâmica e qualidade da aula e, consequentemente, no aprendizado de uma turma.

Esse pensamento define o objetivo deste trabalho de explanar acerca do letramento

* Mestrando do Programa de Pós-Graduação de Letras/UEM. Email: luiz.alzao@hotmail.com **Doutora em Letras, professora da Universidade Estadual de Maringá. Email: profa.alba@gmail.com 
e da multimodalidade e elaborar uma proposta inicial, que poderá indicar um norte para trabalho no ensino fundamental. A ideia está embasada na utilização do filme Diary of a Wimpy Kid (Diário de um Banana) no ensino da língua inglesa. Elencado entre os meios de comunicação mais antigos, o secular cinema é uma das mídias difusoras de cultura mais tradicionais e importantes na construção de significados e de identidade através dos tempos e que, por ter como principal característica o uso de imagens, mantém-se em destaque dentre um número cada vez maior de meios de comunicação que formam o que se denomina de multimídias e que Levy (1999, p. 65) define como aquilo que emprega diversos suportes ou diversos veículos de comunicação.

Segundo Iedema (2003, p. 33), o termo multimodalidade foi introduzido para realçar a importância de levar em conta outras semioses, além da língua em uso, tais como imagem, música, gesto e assim por diante. ${ }^{1}$ Da mesma forma, em relação aos meios de comunicação, Kress (2003, p. 12) afirma que o mundo é dinâmico e que todos nós não nos apercebemos plenamente das mudanças profundas que nos cercam nesse mundo vivo, com suas muitas formas de comunicação, seja no papel ou na tela.

Diante da característica imagética do cinema, é possível notar a relevância do uso de filmes como uma das multimodalidades não só para o propósito de lazer, mas também com objetivos didáticos. Da mesma forma, não deve ser ignorada a importância da utilização das histórias em quadrinhos, das tirinhas, da música, do teatro e até mesmo do videogame, no letramento do educando, haja vista a necessidade do docente se integrar ao contexto do mundo tecnológico dinâmico vivenciado pela sociedade e, mais especificamente, pelo jovem nos dias atuais, pois uma maior proximidade do docente com outras formas de comunicação poderá desenvolver papel relevante no processo ensino/aprendizado.

Embora seja um tema complexo, que engloba muitas nuances, Kleiman (2012, p. 18-19) define o letramento especificamente como um conjunto de práticas sociais que usam a escrita como sistema simbólico e como tecnologia, em contextos específicos, para objetivos específicos. Na mesma linha de raciocínio, Kress (2003, p. 4) argumenta que letramento é um termo que podemos usar quando produzimos mensagens usando letras como meio de gravar uma mensagem. Diante dessas definições, fica evidenciado que o letramento tem grande importância por estar inserido em um contexto de práticas sociais que determinam relações de identidade, conhecimento e poder.

Para Kress (2003, p. 4), a disponibilização de múltiplos modos de comunicação através de novas tecnologias, em particular o modo da imagem, tanto em âmbito estático quanto em movimento, torna o uso dessas multimodalidades natural, fácil, corriqueiro e favorece a interatividade do usuário. Ainda, embora a língua falada vá continuar sendo o modo mais usado na comunicação, a língua escrita vai ser substituída vertiginosamente pela imagem, principalmente nos seguimentos de comunicação pública, com exceção da elite cultural e política, que preferirá a forma escrita. A associação da modalidade escrita com a da imagem através da tela pode causar alterações profundas na forma e na função da escrita e resultará em profundos efeitos cognitivos e afetivos no ser humano. Além

\footnotetext{
1 Tradução.
} 
disso, a mudança para a tela como meio de comunicação vai afetar a relação de poder, com a resistência feroz dos detentores desse poder.

A confirmação de que essa teoria defendida pelo teórico há tantos anos é válida pode ser facilmente comprovada ao se observar a quantidade inimaginável de comunicações realizadas entre pessoas por todo globo terrestre. Através de multimídias como aparelhos celulares, notebooks, tablets etc, são enviados textos acompanhados de fotos, vídeos e emojis, que facilitam a comunicação e o intercâmbio entre pessoas de diferentes culturas no mundo todo de forma rápida, eficiente e muitas vezes divertida. A utilização desses aparelhos conectados à internet está tornando a comunicação cada vez mais dinâmica, pois é recorrente a transmissão de uma mensagem com a utilização unicamente de uma imagem, desacompanhada de um texto, pois ela fala por si mesma.

Diante de um mundo cada vez mais globalizado e dinâmico, pode-se perceber que a utilização de filmes como modalidade mostra-se relevante como ferramenta no ensino, por sua função na construção e divulgação de significados, na construção da identidade do sujeito e na propagação de diferentes culturas para todos os continentes do globo terrestre.

A utilização de tais facilidades em sala de aula, no entanto, pode esbarrar em alguns empecilhos, como a falta de afinidade do professor com as multimídias. Esse problema pode ser oriundo da ausência de matéria curricular específica na formação de novos professores; da grande carga de afazeres burocráticos, que não permite ao professor desfrutar de tempo livre para dedicar-se a essa interação; da resistência dos profissionais a se adaptarem a novas tecnologias; do desinteresse do docente por esses modos; do sentimento de insegurança ou incapacidade de manusear tais mídias ou, ainda, da tentativa de manter-se reconhecido como exclusivo mantenedor e provedor de conhecimento. Esse pensamento, todavia, não se justifica devido à imensurável disponibilidade de informações que qualquer cidadão encontra atualmente para consulta na internet. Hoje em dia, todos têm acesso à informação, portanto o conhecimento está mais acessível à população.

O empecilho para utilização de diferentes modos de comunicação no ensino não esbarra exclusivamente nos problemas citados acima. A indisponibilidade de equipamentos tecnológicos nas escolas pode ser mais um fator de entrave nesse processo de assimilação e utilização de novas modalidades no ensino.

A necessidade dessa assimilação por parte do docente pode ser embasada na afirmação de Luke (2000), que diz:

Uma explicação comumente aceita para a relação entre tecnologia e sociedade tem sido o conceito de determinismo tecnológico. Essa visão sustenta que as tecnologias determinam o comportamento humano, relações sociais, e, na verdade, a própria organização social" (LUKE, 2000, p. 72, tradução nossa).

Portanto, ignorar essa integração da sociedade e, consequentemente, do jovem às novas tecnologias corresponderia a "nadar contra a maré", pois as facilidades oferecidas por essas novidades tecnológicas definem o comportamento de uma sociedade e não há como nem porque tentar estancar ou reverter essa situação. Desse modo, essas multimídias podem ser percebidas como aliadas do professor em sala de aula. 
Diante do exposto, faz-se necessário que este trabalho desempenhe a função de fazer com que o professor se sinta mais confiante no uso da modalidade cinematográfica, com sua capacidade imagética, e a veja como importante aliada na necessidade de sua integração às novas tecnologias nas quais o jovem está imerso na atualidade. Portanto, é necessário que o docente supere barreiras pessoais e, ainda, conte com apoio das autoridades educacionais, que devem apresentar as condições estruturais necessárias para a utilização de novas modalidades no letramento de diversas disciplinas e, assim, desempenhar sua função de maneira mais produtiva, dinâmica e atrativa ao aluno.

\section{FILMES E SUA IMPORTÂNCIA PEDAGÓGICA}

Quando se fala em influência da tecnologia sobre a sociedade, o leitor pode ser levado a pensar exclusivamente em modernos aparelhos tecnológicos como smartphones, tablets, laptops, desktops e mais uma variedade de mídias e seus diversos recursos e aplicativos, deixando no esquecimento o centenário, no entanto, contemporâneo cinema. Conhecido por seu papel determinante nos comportamentos da sociedade e um dos recursos de fácil acesso aos professores para o letramento, o filme é considerado uma modalidade eficiente na construção e difusão de significados.

A teoria de Gunther Kress, na qual ele diz que

[...] enquanto o caminho de leitura da imagem é (relativamente) [grifo do autor], aberta, a imagem por si só e seus elementos são cheios de significados. Não há vagueza, nem vazio. As imagens estão cheias de significados, enquanto que as palavras esperam para serem preenchidas (KRESS, 2003, p. 4, tradução nossa).

deixa claro que a imagem é uma excelente modalidade de letramento a ser utilizada pelo profissional de ensino com sua turma de alunos.

Levy (1999, p. 63) afirma que o processo de recepção de uma mensagem pode acionar diversas modalidades perceptivas, e o cinema falado é um veículo de transmissão de mensagens que envolve tanto o sentido da visão quanto da audição e que Coutinho (2005, p. 3) apresenta como linguagem feita de imagens e sons. Assim, seus recursos audiovisuais são eficazes também para uso em sala de aula por ser constituído de linguagens verbais e não-verbais, através da própria língua, som, imagem, gestos, olhares, efeitos especiais etc. Além disso, por não exigir conhecimento prévio e complexo, a exibição de filmes mostra-se ferramenta multimodal muito interessante no trabalho do professor para o letramento de alunos em qualquer nível escolar.

A argumentação apresentada por Coutinho (2005) é que o cinema tem um potencial para ser utilizado no ensino muito superior ao que ele aparenta ter à primeira vista. Todos os tipos de filmes podem transmitir alguma mensagem útil no processo de formação do indivíduo, contribuindo para a construção de sua identidade. Tal pensamento corrobora a pretensão de trabalhar através de um filme que, além de colaborar com o letramento da língua inglesa, oferece a possibilidade de provocar discussões que contribuam para a compreensão da diversidade cultural do mundo atual.

A relevância da discussão sobre elementos sociais e da utilização das 
multimodalidades no ensino de uma disciplina é defendida por Kress (2003, p. 1), ao afirmar que não é mais possível pensar a alfabetização de forma isolada de uma vasta gama de fatores sociais, tecnológicos e econômicos. Diante disso, fica evidente a importância da sétima arte, dentre outras modalidades, no ensino escolar, para difusão de diferentes culturas e seus diversos aspectos multiculturais no mundo globalizado; na provisão de elementos para conhecimento e argumentação em sala de aula, principalmente associado ao letramento da língua daquela cultura.

Quanto à escolha do gênero a ser utilizado em sala, Sherman (2003, p. 2) disserta que o drama é particularmente valioso porque ilustra o tipo de linguagem interativa que a maioria dos estudantes de língua estrangeira raramente encontra. Entretanto, ela acredita que documentários, seriados ou qualquer outro formato também têm papel relevante no ensino de uma língua estrangeira.

Diante disso, percebe-se que o cinema se constitui grande ferramenta não só no letramento de uma língua, mas se mostra eficaz na divulgação da cultura de um povo e capaz de exercer influência sobre sociedades de diferentes épocas ao retratar todo um contexto cultural como costumes, ideais, discursos ideológicos, religiosos e línguas. Sua influência sobre toda uma geração pode ser observada naquela exercida por James Dean, em seu papel de jovem rebelde no filme Rebel without a cause (Juventude Transviada) de 1955, do diretor Nicholas Ray, que avivou a rebeldia na juventude americana da época e que se espalhou mundo afora. Do mesmo modo, esse fenômeno pode ser notado facilmente nas produções da indústria cinematográfica de Hollywood, que, na maioria das vezes, denotam a força ideológica dos americanos, e os apresenta como donos da razão e salvadores do mundo contra todo o mal existente e inerente ao "outro". Assim, são retratados como heróis, operadores do bem, sempre atacados pelo mal e salvadores do planeta. Da mesma forma, ao fazerem uso desse discurso, justificam a aparente necessidade do domínio do branco sobre o negro, como no filme mudo The Birth of a Nation (O Nascimento de uma Nação), de 1915, de D. W. Griffith, que procura mostrar que os negros são incapazes de seguir regras sociais estabelecidas, o que "autoriza" o surgimento da organização Ku Klux Klan nos Estados Unidos da América para punir os negros com a pena de morte, sem nenhum julgamento legal.

Os discursos ideológicos e a disseminação de sua cultura, no entanto, não são privilégios somente do cinema americano. No outro extremo do planeta, existe a indústria cinematográfica indiana, que alguns estudiosos afirmam ser a segunda maior produtora de filmes do mundo (atrás apenas da Nigéria, que tem $90 \%$ dos mais de mil filmes anuais, produzidos em vídeos caseiros e distribuídos informalmente), composta por estúdios regionais, que procuram resguardar e disseminar, cada um, suas culturas e suas línguas regionais na tentativa de garantir a sobrevivência dessas, de acordo com suas ideologias e identidades.

Datta (2000, p. 72) faz uma análise do percurso do cinema indiano e seu papel na construção de uma identidade nacional, através de vários momentos diferentes, desde a forte influência europeia e hollywoodiana, resultado de um processo de globalização existente já no início do Século XX, particularmente em filmes mudos da sétima arte, num encadeamento de equipe técnica europeia, atrizes euroasiáticas e roteirista e diretor 
indianos filmando narrativas indianas.

A consequência dessa rede colaborativa, ainda segundo Datta (2000, p. 72), é que, em filmes mudos produzidos por parceria indo-germânica, atrizes euroasiáticas recebiam nomes hindus e eram apresentadas como se fossem mulheres hindus, bem-educadas, que interpretavam personagens indianos históricos ou mitológicos, com objetivo de construir um sentimento de indianidade, não só para os expectadores indianos, mas também para os europeus.

Datta (2000, p. 73) destaca que, nas produções puramente indianas do período préindependência, iniciou-se o destaque à figura da mãe, como em Aurat (Mulher - na língua urdu), de Mehboob Khan, da década de 1940, que foi reeditado a cores em 1956, com o título de Mother India (Mãe Índia). Essa película marca o início de um processo de iconização e identificação da mulher e também da nação na consciência nacional, que perdurou por décadas após a independência da Índia. Um desses exemplos é o filme Deewar (Divisória), de 1975, com Nirupa Roy e Amitabh Bachchan, no qual a mulher sofrida, com dois filhos, é abandonada pelo marido, ficando com a responsabilidade de criá-los sozinha. O enredo envereda para um fim trágico quando um dos filhos se torna policial e o outro um criminoso, e se enfrentam mortalmente.

A constante presença da atriz indiana Nirupa Roy em vários filmes com o discurso da representação da mulher como a mãe sofrida lhe valeu a alcunha de "a grande mãe de todos os tempos" em Bollywood, principal produtora de filmes no país. Por outro lado, similarmente, sua constante presença representando deusas mitológicas em outro grande número de filmes fazia com que as pessoas acreditassem em seus poderes e, consequentemente, dirigissem-se a ela para lhe pedirem a benção. Esse comportamento do ser humano demonstra a importância que essa arte tem na construção de sentidos e de identidades, em determinada sociedade.

Para Sangeeta Datta,

O advento da televisão via satélite nos anos 1980 mudou visão do mundo do expectador. As imagens estrangeiras, cultura MTV - tornaram-se parte da experiência vista diariamente. A narrativa do cinema foi rapidamente substituída pela imagem dominante (DATTA, 2000, p. 73 , tradução nossa).

Porém, não ocorreu nenhuma alteração quanto ao discurso ideológico patriarcal e racista, pois a estratégia pós-moderna da paródia e outras produções continuaram não só "autorizando" a dominação do homem sobre a mulher, com o discurso da sexualidade feminina e a masculinidade através do corpo musculoso do homem e agressividade física, como também sobre o não-branco.

Esse meio de representação de construção e transformação de significados culturais, ideológicos e de crenças é tão relevante que Bollywood, estabelecida em Mumbai e com alcance internacional, foi acusada, por vários outros estúdios indianos, de transgredir a cultura do país e de discutir temas controversos. Essa acusação se deve principalmente porque atualmente o estúdio apresenta temáticas diversificadas em suas produções. Nesse contexto, pode ser usado, como exemplo, Bride and Prejudice (Noiva e 
Preconceito), uma paródia do filme Pride and Prejudice (Orgulho e Preconceito), resultado de uma adaptação, realizada em 2004, da obra da romancista inglesa Jane Austin, publicado em 1813. A paródia indiana apresenta a versão de uma família cujas mulheres são letradas, têm voz ativa junto ao patriarca da família, preservam sua cultura e refutam qualquer preconceito e estereótipos atribuídos às mulheres do país.

Toda essa argumentação reforça a convicção de que o cinema é uma importante ferramenta multimodal no letramento de várias disciplinas; na preservação e propagação de diferentes culturas; na construção e difusão de significados através dos discursos, que ficam disponíveis ao acesso de diferentes públicos e diferentes gerações através dos tempos.

\section{O CINEMA COMO FERRAMENTA METODOLÓGICA NO ENSINO DA LÍNGUA INGLESA}

Sabe-se que para se aprender uma língua estrangeira são necessários anos de estudo e dedicação, e o sucesso depende do esforço e aptidão de cada um. Assim, para corresponder a essas diferentes necessidades do educando, o filme é uma das multimodalidades que pode tornar-se grande aliada do docente no letramento de uma língua estrangeira, por ter a capacidade de transmitir ao aluno uma percepção de diversão ao mesmo tempo em que pode trazer aprendizagem, cultura e cativar o interesse do aluno. A linguagem audiovisual do cinema tem, também, a capacidade de produzir significados através de cores, sons, ações, ou da ausência dessas e, até mesmo do silêncio, que pode transmitir alguma mensagem e provocar diferentes efeitos sobre expectadores díspares.

Quanto à funcionalidade do filme como ferramenta de letramento, Sherman (2003, p. 2) defende que um vídeo é um livro de imagens em movimento e que ele dá acesso a lugares, coisas, pessoas, acontecimentos e comportamentos, independentemente do idioma usado, e vale mais que milhares de imagens de dicionários ou de revista. Ela esclarece ainda que o filme ideal a ser utilizado deve trazer em sua composição um assunto familiar aos alunos. Isso pode evitar que o filme se torne tedioso e, assim, desinteressante à turma. Além disso, Jane Sherman afirma que um

[...] vídeo autêntico fornece um vasto recurso linguístico de sotaques atualizados, vocabulário, gramática e sintaxe, e todos os tipos de discursos, o que nos mostra a língua na maioria dos seus usos e contextos - algo que o livro de nenhum curso, nem a sala de aula pode fazer (SHERMAN, p. 2, tradução nossa).

As narrativas desse gênero, baseadas tanto em fatos históricos quanto ficcionais, têm a condição de criar uma grande diversidade de sentimentos em seus expectadores, pela confluência de dois elementos sensoriais importantes na recepção da mensagem: a audição e a visão. Assim, a utilização adequada de filmes pode tornar o aprendizado mais fácil, prazeroso e, consequentemente, transformar a missão do docente menos árdua e monótona tanto para si quanto para a turma. 
Anteriormente à execução da iniciativa de ensinar língua inglesa através de filme, é importante que o professor se assegure da existência de condições físicas e tecnológicas em sua unidade escolar para a execução de sua empreitada. Embora as salas de aulas das escolas estaduais do Paraná sejam equipadas com televisores, é constante a existência de fatores que se apresentam como empecilhos para a sua utilização. Um dos problemas enfrentados pelo docente é a impossibilidade de se utilizar pen-drives com capacidade de armazenamento superiores a dois gigas, devido sua incompatibilidade com esses televisores. Além disso, muitos controles desses televisores não funcionam. Ademais, para que o professor conecte seu notebook particular ao televisor, é preciso que ele desembolse, atualmente, um valor superior a cento e quarenta reais para adquirir um adaptador VGA.

Resolvidos todos esses empecilhos, faz-se necessário que o professor faça uma edição do filme e, assim, o adeque ao seu cronograma de trabalho, haja vista que as películas, na imensa maioria das vezes, são muito mais longas do que o tempo de duração de uma aula. Todavia, o docente deve ficar atento aos critérios utilizados na escolha do filme, pois é de suma importância que o seu tema seja coerente com a faixa etária e nível cultural da turma, sob pena de correr o risco de promover o desinteresse e a desatenção da turma. Dessa forma, é possível fazer uso de episódios que apresentem, além do conteúdo a ser trabalhado, elementos culturais que proporcionem discussão em sala. Além disso, para facilitar a compreensão, é importante que as cenas apresentem ações nas quais haja conexões entre as ações e as falas dos personagens.

Um dos programas que podem ser usados para editar filmes e facilitar o trabalho do professor é o Movie Maker. O próprio professor pode fazer uso de uma das multimodalidades para o seu próprio letramento em como editar um filme, pois é possível acessar diversos tutoriais disponibilizados na internet que podem orientá-lo nessa tarefa, que, embora pareça difícil à primeira vista, não o é. Ao executar essa edição, o professor já deverá perceber uma iniciação significante na sua integração com o mundo multimodal em que os jovens navegam corriqueiramente e com imensa facilidade.

\section{O FILME DIARY OF A WIMPY KID COMO FERRAMENTA DE MULTILETRAMENTO NO ENSINO DA LÍNGUA INGLESA}

Está sendo considerado para esse trabalho com turmas do ensino fundamental o primeiro filme da série Diary of a Wimpy Kid (Diário de um Banana). Uma obra de ficção escrita por Jeff kinney, que teve uma sequência de dez livros publicados, dos quais três já foram transformados em filmes, e o quarto livro, o único que não é ficção, mostra a história de como foram feitas as gravações dos filmes e como os personagens se transformaram em estrelas de Hollywood.

Além da linguagem verbal, o autor dessa obra utiliza-se de linguagem mista ao apresentar desenhos caricatos dos personagens, criados pelo próprio autor. A obra é constituída também de fonte que se assemelha à caligrafia; de escrita sobre as linhas de um caderno, enquanto que a utilização de balões representando as falas e figuras de linguagem, principalmente onomatopeias e metáforas. Essas características da obra transmitem uma aparência de história em quadrinhos, o que torna a leitura mais 
descompromissada e agradável. Esse modelo de composição apresentado no livro é transportado para o filme, o que preserva seu espírito jovial e divertido.

A obra trata, de forma divertida, da problemática do jovem que sai do ensino primário, inicia os estudos no fundamental e depara com um ambiente ameaçador, devido à convivência com uma maioria de garotos maiores e mais fortes que ele e que já se barbeiam. O protagonista do enredo se vê na necessidade de se tornar popular na escola e, ao mesmo tempo, manter-se longe de problemas com tais brutamontes. Dentro desse contexto, Greg tenta conquistar novas amizades já no primeiro dia de aula, mas acaba continuando amigo de Rowley, do primário; um gordinho que ainda carrega consigo hábitos infantis e inocentes que envergonham Greg diante dos outros garotos; e de Gupta, fisicamente menor que Greg, filho de imigrantes indianos que tenta usar sua astúcia para "sobreviver" no mundo dos marmanjos. As atitudes infantis de Rowley colocam Greg em situações embaraçosas, frustrando suas tentativas de se mostrar "descolado", tornar-se um aluno popular e chamar a atenção da garota Holly. Para piorar a situação, o efeito de tudo que Greg faz acaba recaindo de forma positiva sobre seu amigo, Rowley, que vira o queridinho das garotas. Por outro lado, em casa, esse jovem tem que negociar com os pais para conseguir que seus interesses sejam atendidos. Além disso, ele tem que sobreviver ao bullying praticado pelo irmão mais velho.

Os problemas na construção de identidade do sujeito e assimilação de um ambiente diferente daquele ao qual os personagens estavam habituados são apresentados de maneira divertida pelo autor. Esse fator, aliado à identificação dos alunos com os personagens e com a história, desempenha o importante papel de atrair o interesse do aluno/leitor, pois enfrentam os mesmos dilemas na nova etapa escolar, na negociação com amigos e com suas famílias. Esse interesse é de grande valia para a execução do trabalho do docente no processo ensino/aprendizagem não só da língua inglesa, mas também de outras disciplinas.

Para dar início à atividade com o filme Diário de um Banana, o professor pode explicar à turma que o objetivo é adquirir conhecimento do vocabulário, praticar a pronúncia e entrar em contato com elementos culturais de outro país. Além disso, é importante esclarecer que um dos objetivos é fazer uma análise comparativa entre as situações representadas pelos personagens e as vividas por eles em seu dia a dia, uma vez que o enredo do filme se refere ao nível escolar em que eles se enquadram.

É importante que o professor lhes informe que foi feita uma edição do filme para que esse se adequasse ao tempo da duração da aula. Embora o trabalho seja com base em partes da obra, é interessante que o docente conte a estória do filme para que a sala comece a se inteirar do enredo; apresente elementos culturais praticados principalmente pela população estadunidense, como o dia das bruxas, que vão auxiliar a compreensão de elementos daquela cultura e contribuir para a compreensão do todo, pois, de acordo com Sherman (2003, p. 5), assistir a um filme que você não entende pode ser uma experiência muito negativa. Entretanto, para manter o interesse da turma, deve-se evitar esclarecer todos os detalhes da estória.

O profissional de ensino poderá desenvolver o trabalho apresentando o filme conforme sugestão a seguir: no primeiro passo, o professor poderá editar uma sequência 
do filme sem as legendas e com o volume minimizado, ou, caso haja algum impedimento técnico, colar jornal na parte inferior do vídeo para encobrir as legendas. $\mathrm{O}$ resultado esperado com isso é que os alunos extraiam significados do enredo através da linguagem visual oferecida pelo filme. Ao fazer esse procedimento, o professor estará simulando um filme mudo. Além disso, a apresentação do filme sem legendas pode evitar que a turma desvie sua atenção para tentar compreender alguma palavra. Ainda, com a finalidade de evitar que os alunos estranhem a apresentação do filme sem som, o professor pode fazer uma breve explanação sobre o cinema mudo e suas peculiaridades nas apresentações em cinemas no início do século XX, como o uso de piano no palco para apresentação de trilha sonora.

Após apresentar o filme "mudo", o professor pode dividir a sala em equipes, com a quantidade de alunos que achar conveniente para a atividade, nominar os grupos e solicitar que cada grupo conte o que compreendeu do filme. Assim, é possível ter uma percepção do que a turma entendeu das mensagens apresentadas somente com linguagem visual. Uma forma de estimular um clima de competição entre eles e mantê-los interessados para os próximos passos é anotar no quadro o que cada grupo assimilou.

O segundo passo pode ser a apresentação do episódio com volume, entretanto, ainda sem as legendas. Este procedimento poderá ser feito mais de uma vez. Espera-se, com isso, que a turma tenha um nível de compreensão maior do episódio, pois mesmo que o aluno não tenha familiaridade com a língua inglesa, é possível que, agora utilizando a visão e a audição, ele identifique alguma palavra que se somará à sua assimilação dos significados alcançada no contexto da edição muda do filme. Ao se concretizar essa expectativa, o professor poderá anotar, no quadro, as palavras assimiladas pelos referidos grupos. Nesse momento, o sentimento de competitividade entre os grupos poderá ser alimentado ao elencar qual deles compreendeu maior número de palavras. Espera-se que a partir desse estágio o clima de competição e a expectativa de uma aula interessante já estejam instituídos.

No terceiro passo, o professor pode apresentar uma edição do filme legendado. Espera-se que agora com os diálogos e as legendas, o aluno tenha aumentado sensivelmente sua percepção do todo ao reconhecer, além de uma palavra pronunciada, também algum vocábulo grafado. Nesse estágio, é interessante que o professor reprise cada cena, fala a fala, por três vezes, para que aumente a possibilidade de a turma assimilar a pronúncia. Contudo, para evitar que o trabalho seja prejudicado pela timidez de alguns alunos e incentivá-los a pronunciar vocábulos em uma língua estrangeira, o docente poderá solicitar que cada grupo repita as falas dos personagens, e não individualmente. Ele deverá, também, dar prosseguimento à anotação de pontos de acordo com a pronúncia de cada grupo, para evitar que o interesse dos alunos diminua.

Nesse momento da atividade, após o exercício da pronúncia, tendo em conta que Sherman $(2003$, p. 8) defende que, ao utilizar vídeo, a compreensão do todo raramente vem das palavras avulsas, o profissional pode auxiliar a percepção do todo com perguntas direcionadas, que os levem a optar pela resposta correta entre duas ou mais opções apresentadas. Faz-se necessário dar sequência à anotação dos acertos de cada time.

Após esse exercício, o docente poderá solicitar que os grupos façam um trabalho 
de tradução com o auxílio de um dicionário, para que possam dar continuidade à aprendizagem do vocabulário da língua inglesa. Essa tradução poderá ser focada nos elementos da oração, a começar pelo sujeito, verbos e, posteriormente, nos adjetivos, artigos, preposições e assim por diante. Desse modo, as junções das palavras compreendidas individualmente agora vão dar sustentação à formação do todo pelas partes, como em um quebra-cabeça. Espera-se com isso que os alunos sintam que o resultado é compensador ao verem que é possível aprender uma língua estrangeira de forma divertida.

Agora que a turma já tem o conhecimento de todo o vocabulário e das situações do episódio, o professor poderá trabalhar com tempos do verbo. Nesse caso, para explicar o gerúndio, é interessante reproduzir a cena e pausar antes de uma das ações dos personagens e perguntar o que ele está fazendo, para o futuro o que ele fará. Todavia, para a compreensão do verbo no passado, é preciso primeiro passar a cena e somente depois questionar o que o personagem fez. Após esses exercícios, as perguntas poderão ser direcionadas a possíveis ações dos próprios alunos utilizando os verbos trabalhados com os personagens. Isso poderá trazer um sentimento de proximidade dos alunos com as ações dos personagens.

A identificação da turma com eventos da obra cinematográfica $O$ diário de um banana, se selecionada e utilizada para uma turma de faixa etária adequada ao seu conteúdo, além de ter a capacidade de tornar a aula mais interessante, divertida e bastante instrutiva para o aluno, pode oferecer ao educador a possibilidade de sair do aspecto formal do ensino puramente da língua e levar a turma a um ambiente de discussões sobre alguns aspectos apresentados na película, que podem estar relacionados ao cotidiano dela. Nesse caso, pode-se levar a turma a explorar a questão do bullying; a dificuldade que o aluno enfrenta em se adaptar a uma nova escola, ou a uma nova turma e a necessidade de autoafirmação inerente a sua faixa etária. Além disso, o filme tem a capacidade de produzir significados marcantes na vida do aluno e contribuir fortemente, não só com o ensino da língua em questão, mas também com a formação da cultura e da identidade do sujeito.

Espera-se, com isso, que a utilização desse filme no letramento da língua inglesa tenha cumprido a função de proporcionar facilidade de aprendizado aos alunos e facilidade no ministrar da aula ao docente e que a turma tenha se empenhado na discussão das problemáticas enfrentadas cotidianamente. Além disso, a missão de divulgação de aspectos de outra cultura deverá ter sido atendida.

\section{CONSIDERAÇÕES FINAIS}

Ultrapassadas as dificuldades estruturais e pessoais, a utilização de filmes como ferramenta de letramento em sala de aula possibilita uma gama de exercícios bastante ampla e dependerá da criatividade e do interesse de cada profissional de ensino para tornar a aula interessante e produtiva.

O desenvolvimento vertiginoso de novos meios de comunicação através de novas tecnologias possibilita a comunicação instantânea em nível global, assim como o deslumbramento e a inserção meteórica da sociedade e, principalmente, do jovem nessas 
modalidades tecnológicas de transmissão e recepção de mensagens. À primeira vista, toda essa gama de novas multimodalidades utilizadas na transmissão de mensagens e cultura pode passar ao profissional do ensino a impressão que o centenário cinema é um meio de construção de significados e de identidades inadequado e até mesmo ultrapassado. Contudo, a linguagem visual, uma das principais características do cinema, o mantém atualizado e eficiente na difusão de discursos, de cultura e de construção de significados. A sua eficácia é percebida pelos usuários na emissão e recepção de significados através de vídeos, cujas imagens falam por si mesmas, trafegados pela internet por todo o globo terrestre.

Ao levar em consideração que atualmente o jovem forma uma via de mão dupla por interagir e exercer influência sobre os caminhos a serem tomados por alguns produtores cinematográficos, através das fan fictions, é válido ressaltar que a sétima arte continua inserida no conjunto de mídias que direcionam o comportamento da sociedade e, pelo que parece, sempre estará mais atualizada do que nunca.

Essa integração do cinema com a juventude o coloca em um posicionamento de modalidade atualizada de letramento interessante no ensino de inúmeras disciplinas. No entanto, essa modalidade somente poderá se traduzir em resultados positivos no ensino escolar se o docente levar em consideração sua relevância e se propuser a tirar proveito da eficiência e da força de comunicação e produção de significados que ele tem junto à juventude.

\section{REFERÊNCIAS}

AUSTIN, J. Pride and Prejudice. Publicação: Thomas Egerton, 1813.

CHADHA, G. Bride and Prejudice, 2004.

COUTINHO, L. M. Refletindo Sobre a Linguagem do Cinema. Ministério da Educação, Boletim 02, 2005. p. 3.

DATTA, S. Globalisation and Representations of Women in Indian Cinema. Social Scientist. Brighton. Vol. 28, No. 3/4. 2000. p. 71-82.

KINNEY, J. Diário de um Banana. Tradução: Antônio de Macedo Soares. Ed. V\&R. Direção: Thor Freudenthal. Produção: Nina Jacobson e Brad Simpson. Fox Filmes, 2008.

KLEIMAN, A. Modelos de Letramentos e as Práticas de Alfabetização na Escola. In: Kleiman, A. Os Significados do Letramento: uma nova perspectiva sobre a prática social da escrita. Campinas, Ed. Mercado das Letras, 2012, 2. ed. 2012. p. 15.

KRESS, G. The Literacy in the New Media Age. Ed. Routledge, 2003. p. 1, 4, 17.

LEVY, P. Cibercultura, Ed. 34 Ltda. Tradução Carlos Irineu da Costa, 1999. p. 63

LUKE, C. Cyber-schooling and Technological Change. In: Cope and Kalantzis, Multiliteracy: literacy learning and the design of social future, Ed. Routledge, 2000. p. 72. 
SHERMAN, J. Using Authentic Video in the Language Classroom. UK: Cambridge University Press, 2003. p. 19.

Recebido em: 05/06/2017

Aprovado em: 23/07/2017

Publicado em: 01/02/2018 